\title{
Acute bilateral putaminal haemorrhagic necrosis in methanol poisoning
}

\author{
Sibi Thirunavukkarasu, Pradeep Pankajakshan Nair, Vaibhav Wadwekar
}

Department of Neurology, Jawaharlal Institute of Postgraduate Medical Education and Research, Pondicherry, India

\section{Correspondence to} Dr Vaibhav Wadwekar, vaibhavwadwekar@yahoo.co.in

\section{DESCRIPTION}

A 30-year-old man without significant past illness was admitted to the neurology intensive care unit with a 2-day history of altered level of consciousness, vomiting and vision loss. History revealed that he had consumed unknown amounts of unbranded alcohol 4 days earlier. The clinical examination revealed a Glasgow Coma Scale of E2V2M4, bilaterally dilated pupils, optic disc oedema, normal deep tendon reflexes and flexor plantar responses bilaterally. Arterial blood gas analysis showed severe metabolic acidosis ( $\mathrm{pH}$ 7.11). Further evaluation revealed high anion (40 mEq/L; normal $8-16 \mathrm{mEq} / \mathrm{L})$ and

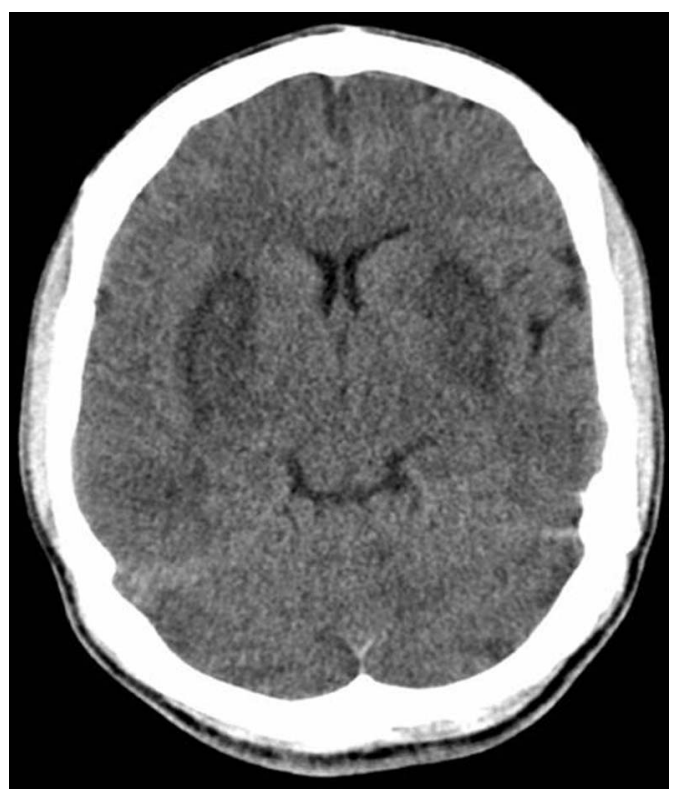

Figure 1 Non-contrast CT image of the brain showing bilateral hypodensity of the putamen. osmolar gap (31 mOsm/L; normal $<10 \mathrm{mOsm} / \mathrm{L}$ water). Brain CT scan without contrast (figure 1) showed bilateral putamen hypodensities. Based on the history, clinical findings and investigations, a diagnosis of methanol poisoning was made. The patient underwent one cycle of haemodialysis, following which the level of consciousness improved. MRI on day 11 after alcohol consumption revealed bilateral putaminal lesions (figure $2 \mathrm{~A}-\mathrm{C}$ ). These lesions were haemorrhagic as evidenced by their hyperintense appearance on T1 (figure 2A) and blooming on gradient echo sequence (figure 2D). The patient's sensorium recovered completely on discharge, but his vision did not improve. His vision was finger counting at $1 \mathrm{ft}$ at the time of discharge. Methanol is metabolised to formic acid which is responsible for most of its toxic manifestations such as vision loss, abdominal pain, vomiting, altered sensorium, seizures and coma. The very few aetiologies that have been described to cause haemorrhagic necrosis of the putamen include methanol ingestion, carbon monoxide poisoning, cyanide poisoning, Leigh's disease and deep venous sinus thrombosis. ${ }^{12}$

\section{Learning points}

- MRI of the brain can assist in the diagnosis of methanol poisoning due to its characteristic findings.

- The combination of visual loss, acidosis and bilateral putaminal haemorrhagic necrosis on imaging is helpful in making a diagnosis of methanol poisoning as a history of methanol ingestion may not always be forthcoming.

\section{To cite:}

Thirunavukkarasu S, Nair PP, Wadwekar V. BMJ Case Rep Published online: [please include Day Month Year] doi:10.1136/bcr-2013201026 


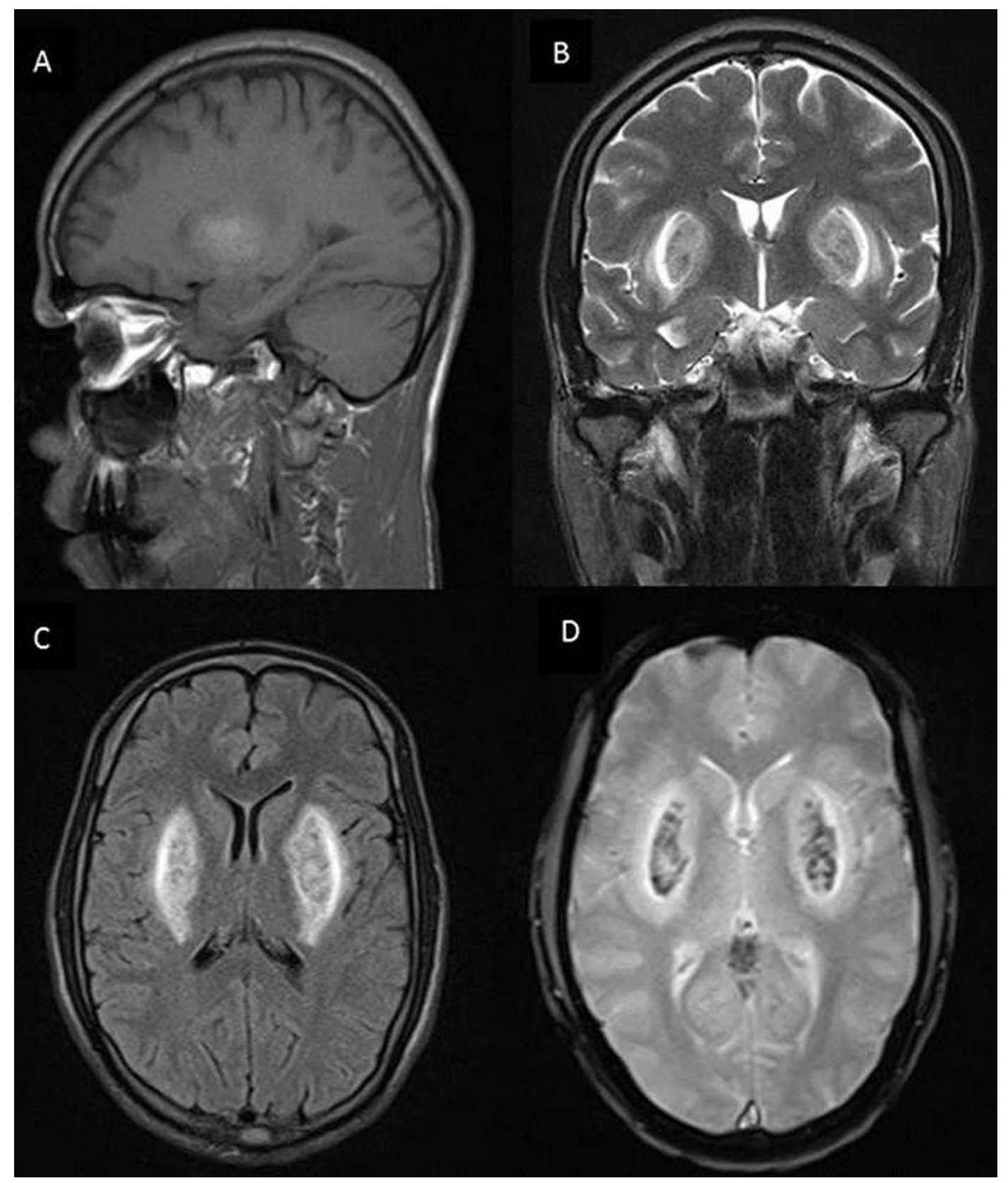

Figure 2 Brain MRIs without contrast showing bilateral hyperintense putaminal lesions in: (A) sagittal T1-weighted sequence; (B) coronal T2-weighted sequence; and (C) axial fluid-attenuated inversion-recovery sequence. (D) Gradient-echo sequence shows bilateral blooming in the putaminal region suggestive of haemorrhages.

Contributors ST was involved in the data acquisition and drafting of the manuscript. PPN participated in the drafting, revising and conception of the manuscript. VW participated in the drafting and revising of the manuscript.

\section{Competing interests None.}

Patient consent Obtained.

Provenance and peer review Not commissioned; externally peer reviewed.

\section{REFERENCES}

1 Penney Gaul H, Wallace CJ, Auer RN, et al. MR findings in methanol intoxication. AJNR Am J Neuroradiol 1995;16:1783-6.

2 Blanco $M$, Casado R, Vázquez $F$, et al. CT and MR imaging findings in methanol intoxication. AJNR Am J Neuroradiol 2006;27:452-4. 
Copyright 2013 BMJ Publishing Group. All rights reserved. For permission to reuse any of this content visit http://group.bmj.com/group/rights-licensing/permissions.

BMJ Case Report Fellows may re-use this article for personal use and teaching without any further permission.

Become a Fellow of BMJ Case Reports today and you can:

- Submit as many cases as you like

- Enjoy fast sympathetic peer review and rapid publication of accepted articles

- Access all the published articles

- Re-use any of the published material for personal use and teaching without further permission

For information on Institutional Fellowships contact consortiasales@bmjgroup.com

Visit casereports.bmj.com for more articles like this and to become a Fellow 